\begin{tabular}{|c|c|}
\hline Title & Synthesis of an Ellagitannin Component, the Macaranoyl Group with a Tetra ortho-Substituted Diaryl Ether Structure \\
\hline Author(s) & $\begin{array}{l}\text { Hashimoto, Haj ime; I shimoto, T akay uki; Konishi, Hay ato; Hirokane, T sukasa; W akamori, Shinnosuke; Ikeuchi, } \\
\text { Kazutada; Y amada, Hidetoshi }\end{array}$ \\
\hline Citation & $\begin{array}{l}\text { Organic letters, 22(17), 6729-6733 } \\
\text { https://doi.org/10.1021/acs.orglett.0c02066 }\end{array}$ \\
\hline Issue Date & $2020-09-04$ \\
\hline Doc URL & http:/hdl.handle.net/2115/82528 \\
\hline Rights & $\begin{array}{l}\text { This document is the A ccepted Manuscript version of a Published Work that appeared in final form in Organic Letters, } \\
\text { copyright c A merican Chemical Society after peer review and technical editing by the publisher. To access the final } \\
\text { edited and published work see [insert A CS A rticles on Request author-directed link to Published W ork, see } \\
\text { https://pubs.acs.org/doi/10.1021/acs.orglett.0c02066 }\end{array}$ \\
\hline Tyре & article (author version) \\
\hline File Information & Org. Lett.22-17_6729-6733.pdf \\
\hline
\end{tabular}

Instructions for use 


\title{
Synthesis of an Ellagitannin Component, the Macaranoyl Group with a tetra-ortho-Substituted Diaryl Ether Structure
}

\author{
Hajime Hashimoto, ${ }^{\dagger}$ Takayuki Ishimoto, ${ }^{\dagger}$ Hayato Konishi, ${ }^{\dagger}$ Tsukasa Hirokane, ${ }^{\dagger}{ }^{\S}$ Shinnosuke Waka- \\ mori, ${ }^{\dagger}$ Kazutada Ikeuchi, ${ }^{\dagger+,}{ }^{\dagger}$ Hidetoshi Yamada $^{\dagger}$
}

${ }^{\dagger}$ School of Science and Technology, Kwansei Gakuin University, 2-1 Gakuen, Sanda, Hyogo 669-1337 Japan

${ }^{\ddagger}$ Department of Chemistry, Faculty of Science, Hokkaido University, Kita 10, Nishi 8, Kita-ku, Sapporo, 060-0810 Japan

Supporting Information Placeholder

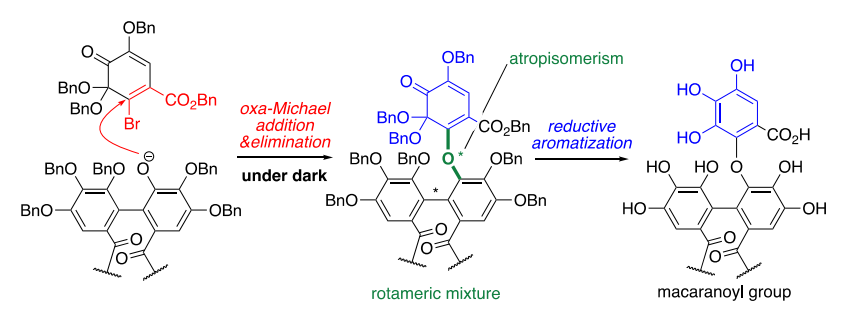

\begin{abstract}
Herein, a practical synthesis of the macaranoyl group contained in ellagitannins, i.e., a C-O digallate structure with a tetra-ortho-substituted diaryl ether bond, is described. The methodology involved an oxa-Michael addition/elimination reaction between a brominated ortho-quinone monoketal and a phenol with a hexahydroxydiphenoyl moiety in the presence of 18-crown-6 under dark conditions, followed by reductive aromatization. The existence of rotamers originating from the constructed ether moiety is discussed as well.
\end{abstract}

Ellagitannins are a class of natural polyphenols. To date, more than a thousand ellagitannins have been isolated. ${ }^{1}$ Their general structure comprises D-glucose esterified with galloyl and axially chiral hexahydroxydiphenoyl (HHDP) groups, biosynthesized via $\mathrm{C}-\mathrm{C}$ coupling of two galloyl groups in pentagalloyl-D-glucose. ${ }^{2}$ Ellagitannins additionally contain $\mathrm{C}-\mathrm{O}$

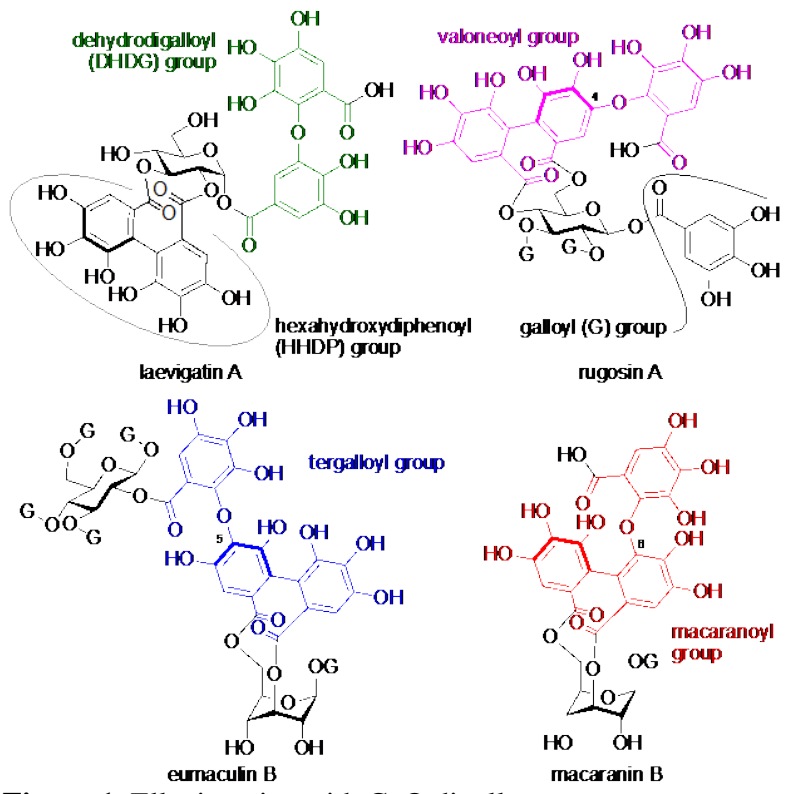

Figure 1. Ellagitannins with $\mathrm{C}-\mathrm{O}$ digallate structures. digallate moieties, comprising a diaryl ether structure wherein two galloyl groups are connected via a C-O bond. Ethereal linkages between a galloyl group and other components, e.g. an HHDP group, have also been found in nature, and form more complicated $\mathrm{C}-\mathrm{O}$ digallate structures. ${ }^{3}$ Dehydrodigalloyl (DHDG), valoneoyl, tergalloyl, and macaranoyl groups are representative components (Figure 1). As exemplified by eumaculin B, these components can oligomerize a monomeric ellagitannin via esterification of a carboxyl group in the motif with a hydroxy group of a glucose moiety in another ellagitannin, resulting in broad structural diversity of the ellagitannins. ${ }^{4}$

C-O Digallate structures have previously been constructed by three groups. Feldmann et al. and Abe et al. synthesized the DHDG group using independent strategies, ${ }^{5,6}$ and Abe et al. additionally prepared the valoneoyl group. ${ }^{7}$ Recently, we reported a unified synthetic strategy for DHDG, valoneoyl, and tergalloyl groups. ${ }^{8} \mathrm{Nev}-$ ertheless, their synthetic application to the macaranoyl group has not been explored as yet.

Nishioka and coworkers have previously synthesized a methylated macaranoyl analogue $\mathbf{1}$, for the structural determination of this component of natural ellagitannins. They achieved this via Ullmann coupling between an aryl bromide, prepared from 2, and a second aryl bromide $\mathbf{3}$ (Scheme 1a). ${ }^{9}$ However, the yield was low, and two isomers of $\mathbf{1}$, derived from the undesired bromination products of $\mathbf{2}$, were also generated. Herein, we describe a practical synthesis of the macaranoyl group achieved by adaption of our synthetic procedure for the $\mathrm{C}-\mathrm{O}$ digallate structures. 
Scheme 1. (a) Reported method for synthesizing the macaranoyl group. (b) Our synthetic method for $\mathrm{C}-\mathrm{O}$ digallate structures.
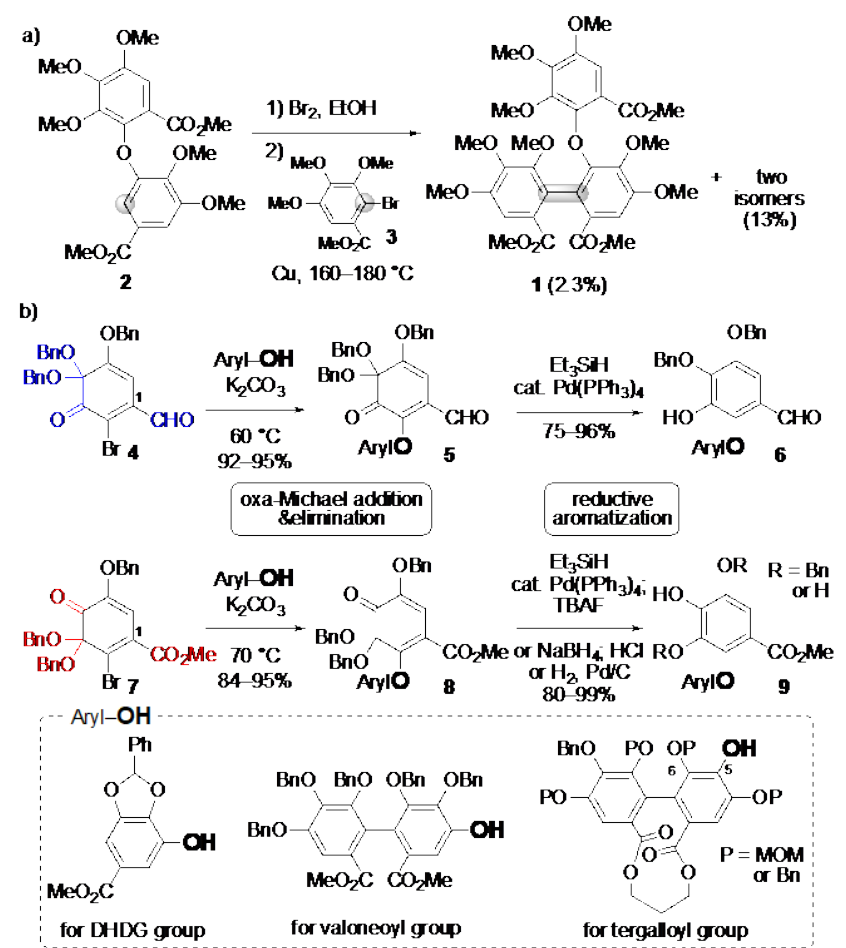

Our unified synthetic method for DHDG, valoneoyl, and tergalloyl groups is described in Scheme $1 \mathrm{~b} .{ }^{8}$ Orthoquinone monoketal $(o-Q k) 4^{8 \mathrm{a}}$ was used as an electrophile, and the oxa-Michael addition of a phenol bearing a galloyl or HHDP moiety to $\mathbf{4}$, followed by elimination of the bromine atom gave 5 . Subsequent treatment of 5 with $\mathrm{Et}_{3} \mathrm{SiH}$ and a catalytic amount of $\mathrm{Pd}\left(\mathrm{PPh}_{3}\right)_{4}$ resulted in reductive aromatization of $\mathbf{5}$ to form $\mathbf{6}$. We further developed a novel $o-Q k$ 7, ${ }^{8 \mathrm{~b}}$ wherein the ketone and ketal locations in $\mathbf{4}$ were reversed. Thus, the electrophilic carbon of $\mathbf{7}$ was more reactive than that of $\mathbf{4}$ by acquiring an additional conjugation effect from the ketone, which allowed the oxa-Michael/elimination reaction despite the replacement of the aldehyde at the 1-position of $\mathbf{4}$ with a methyl ester. This modification had further positive effects on the subsequent reaction; in addition to reductive conditions involving $\mathrm{Et}_{3} \mathrm{SiH}$ and $\mathrm{Pd}\left(\mathrm{PPh}_{3}\right)_{4}, \mathrm{NaBH}_{4}$ reduction followed by acidic workup, as well as hydrogenolysis, could both induce the reductive aromatization of $\mathbf{8}$ to supply $\mathbf{9}$. As these two electrophiles enabled the formation of a tetra-ortho-substituted diaryl ether structure in the tergalloyl group, wherein the ethereal bond is located at the 5-oxygen of the HHDP group, this method may also form the corresponding bond in the macaranoyl group. However, this transformation appears challenging because the $\mathrm{C}-\mathrm{O}$ bond must be constructed at a more crowded position (6-O), implying that steric repulsion may be problematic for the synthesis.

To construct the macaranoyl group, we initially used electrophile 10, wherein the methyl ester of $\mathbf{7}$ was replaced with an aldehyde (Scheme 2). o-Qk 10 is more electrophilic than 7 owing to the strong inductive effect of the aldehyde and is hence expected to realize the desired reaction. To minimize steric hindrance at the reaction site, phenol $\mathbf{1 1}^{10}$ was selected as the nucleophile, wherein all the oxygen atoms of the HHDP group, except for 6-O, were methylated. $o$-Qk 10 was prepared in 97\% yield via phenyliodine(III) bis(trifluoroacetate) (PIFA)-mediated oxidation ${ }^{11}$ of phenol $12^{10}$ in the presence of excess benzyl alcohol $(\mathrm{BnOH})$. Although the synthesis of $\mathbf{7}$ also provided its regioisomer, ${ }^{8 \mathrm{~b}} \mathbf{1 3}$, the corresponding regioisomer of $\mathbf{1 0}$, was not formed. The reaction of $\mathbf{1 0}$ with $\mathbf{1 1}$ proceeded smoothly to furnish the desired product 14 in $91 \%$ yield. However, subsequent reductive aromatization using $\mathrm{Et}_{3} \mathrm{SiH}$ and catalytic $\mathrm{Pd}\left(\mathrm{PPh}_{3}\right)_{4}$ to obtain 15 failed, instead affording 11 as the major product. Other reaction conditions such as Luche reduction ${ }^{12}$ and hydrogenolysis were also attempted; while no desired product was obtained, 11 was generated (Supporting Information (SI)-S2). Hydride reduction failure may be explained by the high electrophilicity of the $\alpha, \beta$-unsaturated aldehyde moiety of 14 , which preferred an attack by $\mathrm{H}^{-}$on the $\beta$-carbon to eliminate $\mathbf{1 1}$. Under hydrogenolysis conditions, in addition to reductive aromatization of 14 and removal of two Bn groups in 15, the aldehyde function is likely being reduced. Thus, we assumed that the production of $\mathbf{1 1}$ was attributed to the oxidation of the 1-aryloxy-2,3,4-trihydroxy-6methylbenzene ring in air.

Scheme 2. Attempt to synthesize the macaranoyl group using oQk 10.

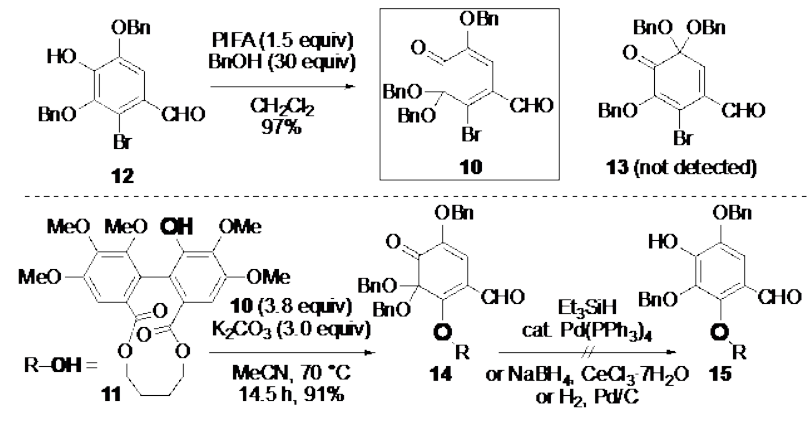

Therefore, we conducted experiments using $o-\mathrm{Qk} 7$, the reactivity of which was enhanced owing to the mesomeric effects between the ketone and ester. The oxa-Michael addition/elimination reaction between 7 and 11 gave the coupling product 16 in 47\% yield (Scheme 3a). ${ }^{13}$ However, the reaction required over 5 days and various byproducts were detected by TLC and MS analysis. One of the major byproducts was identified as 17; its structure was confirmed by comparing its spectral data with that of 17, synthesized in $97 \%$ yield via oxa-Michael addition/elimination reaction of 7 and phenol 18. ${ }^{8 \mathrm{~b}}$ Because the isolated yield of $\mathbf{1 7}$ was $32 \%$, it was expected that suppressing this side reaction would increase the yield of 16. We established that $\mathbf{1 7}$ was generated via self-aromatization of $\mathbf{7}$ under light irradiation. The ${ }^{1} \mathrm{H}$ NMR spectrum of $\mathbf{7}$ in chloroform- $d$ after irradiation with a fluorescent light (Panasonic, FL20SS·EX-N/18) for $24 \mathrm{~h}$, displayed signals corresponding to benzaldehyde and phenol 18 along with those attributed to 7 (SIS3). The amounts of these two products increased continually over time, with a disappearance of $\mathbf{7}$ observed after 4 days. The production of $\mathbf{1 7}$ involved the generation of $\mathbf{1 8}$ in situ, followed by its reaction with the remaining 7 . This side reaction was not detected in the previous study that utilized 7 because those reactions were complete within a shorter time $(\leq 10 \mathrm{~h}){ }^{8 \mathrm{~b}}$ Thus, prolonged reactions with 7 should be conducted under dark conditions. We further hypothesized that the addition of 18-crown- 6 would enhance the reactivity of $\mathbf{1 1}$ because of the formation of the salt-free phenolate anion. ${ }^{14}$ Based on this consideration, we conducted the following experiment. To a suspension of $\mathbf{1 1}$ and $\mathrm{K}_{2} \mathrm{CO}_{3}$ in acetonitrile in a reaction flask wrapped with aluminum foil, 7 and 18-crown- 6 were added, and the mixture was stirred at $71^{\circ} \mathrm{C}$. The desired reaction was complete within $49 \mathrm{~h}$, which was $83 \mathrm{~h}$ shorter than the time required for reaction in Scheme 3a; $\mathbf{1 6}$ was obtained in 66\% yield (Scheme 3b). Subsequent reductive aromatization of $\mathbf{1 6}$ proceeded smoothly under Luche reduction conditions ${ }^{12}$ to supply phenol 19 with a macaranoyl structure in $98 \%$ yield. 
Scheme 3. (a) Formation of byproduct $\mathbf{1 7}$ in the reaction of $\mathbf{1 1}$ with 7. (b) Optimized oxa-Michael addition/elimination reaction using 7 and transformation into phenol 19.

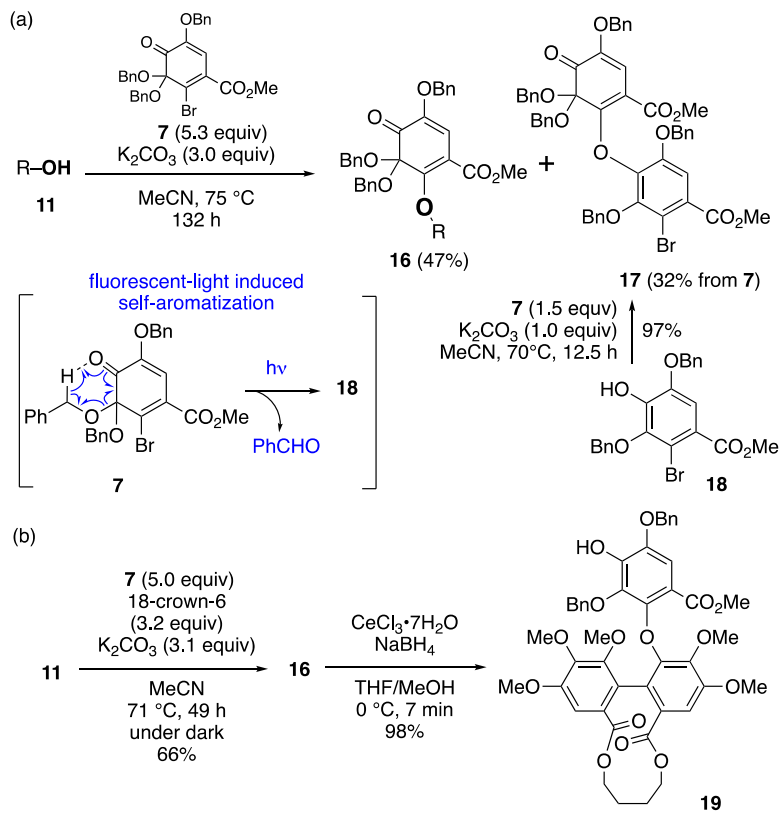

We next attempted a practical synthesis of the macaranoyl group. Because removal of methyl protecting groups of phenolic hydroxy groups is difficult, benzyl $(\mathrm{Bn})$-protecting groups are frequently used in ellagitannin synthesis owing to their tolerance of various reaction conditions and ease of removal via hydrogenolysis. ${ }^{8 a, 15}$ Thus, an oxa-Michael addition/elimination reaction using an analogue of 11, wherein its methyl groups were substituted by Bn groups, would be more practical. Additionally, we decided to change the ester moiety of 7 because selective hydrolysis of the methyl ester in the presence of other esters, formed between D-glucose and HHDP/galloyl groups, is difficult. Replacement with a benzyl ester would facilitate the release of the carboxylic group, which expedites the synthesis of oligomeric ellagitannins containing the macaranoyl group. ${ }^{16}$ Thus, we focused on the oxa-Michael addition/elimination reaction of phenol $\mathbf{2 0}^{10}$ and $o-\mathrm{Qk} \mathbf{2 1}$.

The synthetic method of $\mathbf{2 1}$ is shown in Scheme 4a. Transformation of alcohol $\mathbf{2 2}^{8 \mathrm{~b}}$ into carboxylic acid 23 via 2,2,6,6tetramethylpiperidine 1-oxyl (TEMPO)-mediated oxidation with $\mathrm{PhI}(\mathrm{OAc})_{2}$ and $\mathrm{NaClO}_{2},{ }^{17}$ benzylation of $\mathbf{2 3}$, and removal of the allyl group provided phenol 24. PIFA-mediated oxidation of $\mathbf{2 4}$ into $\mathbf{2 1}$ was performed in the presence of 2.0 equiv of $\mathrm{BnOH}$ to generate a crude product mixture of $\mathbf{2 1}$ and $\mathbf{2 5}$ in a 5.8:1 ratio. Undesired 25 was decomposed during purification by silica gel chromatography, and $\mathbf{2 1}$ was isolated exclusively in $\mathbf{7 3} \%$ yield, suggesting that $\mathbf{2 5}$ possesses similar properties to the regioisomer of $o-\mathrm{Qk} 7 .^{8 \mathrm{~b}}$ Similar to 7, o-Qk 21 underwent light-mediated self-aromatization to afford $\mathbf{2 4}$ and benzaldehyde (SI-S4).

The oxa-Michael addition/elimination reaction of $\mathbf{2 0}$ and $\mathbf{2 1}$ proceeded under conditions analogous to those of the reaction between 11 and 7 (Scheme 4b). Even though the reaction site of $\mathbf{2 0}$ is more hindered than that of 11, owing to the surrounding Bn groups, the reaction was completed within $43 \mathrm{~h}$ and gave the desired product 26 in 64\% yield, illustrating the robust reactivity of $\mathbf{2 1}$. While $\mathbf{2 6}$ also underwent self-aromatization under light to slowly degrade into phenol 27 and benzaldehyde, it remained stable for a month when kept in the dark (SI-S5). Interestingly, the ${ }^{1} \mathrm{H}$ and ${ }^{13} \mathrm{C}$ NMR spectra of $\mathbf{2 6}$ in acetonitrile- $d_{3}$ at $24{ }^{\circ} \mathrm{C}$ displayed signal duplication. For example, the proton and carbon signals for the 5' - and 2' '-positions were detected at $\delta$ 6.22/5.94 and 98.3/95.9, respectively. The four substituents located adjacent to the formed ether bond impart rigidity to it and impede bond rotation, appearing to generate a $\mathrm{C}-\mathrm{O}$ chiral axis. ${ }^{18}$ Although 26 also contains a $\mathrm{C}-\mathrm{C}$ chiral axis in the biphenyl structure, no examples exist of $\mathrm{C}-\mathrm{C}$ chiral axis rotation in protected HHDP groups. Thus, we rationalized that the duplication of signals is attributed to the presence of rotamers, arising from the $\mathrm{C}-\mathrm{O}$ chiral axis. ${ }^{19}$ No coalescence of the signals pairs was observed in the ${ }^{1} \mathrm{H}$ NMR spectrum despite elevating the temperature to $75^{\circ} \mathrm{C}$, which suggested that the rotation energy barrier was sufficiently high. As self-aromatization of $\mathbf{2 6}$ was observed in this experiment (SI-S6), we did not measure the ${ }^{1} \mathrm{H}$ NMR spectra at higher temperatures.

We next transformed 26 into the unprotected macaranoyl derivative (Scheme 4b). Treatment of $\mathbf{2 6}$ with $\mathrm{NaBH}_{4}$ followed by $1 \mathrm{M}$ aqueous $\mathrm{HCl}$ induced reductive aromatization, affording 27 in 91\% yield. Selective hydrolysis of diester moieties bearing the propane tether, followed by the hydrogenolysis of obtained $\mathbf{2 8}$ provided the desired compound $\mathbf{2 9}$. The macaranoyl structure of $\mathbf{2 9}$ was confirmed via the transformation of $\mathbf{2 6}$ into known compound $\mathbf{1}$. Following the reductive aromatization of 26, and removal of all the Bn groups via hydrogenolysis, the treatment of obtained $\mathbf{3 0}$ with TMS diazomethane ${ }^{20}$ gave a nona-methylated compound 31. Methanolysis to cleave the Scheme 4. (a) Synthesis of novel o-Qk 21. (b) Synthesis of the macaranoyl group.
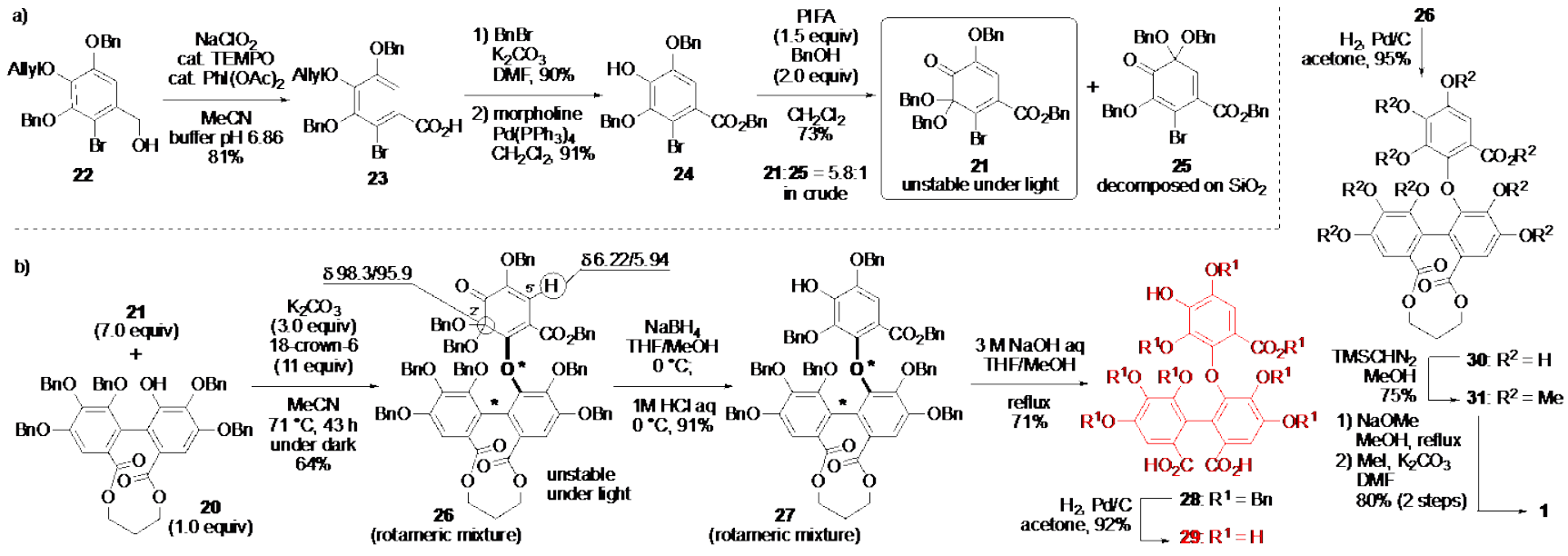
propane tether of $\mathbf{3 1}$ using $\mathrm{NaOMe}$ in $\mathrm{MeOH}$ produced $\mathbf{1}$ and the product of partial hydrolysis, resulting from the presence of a small amount of water contained in the reaction mixture. Thus, the crude product was exposed to $\mathrm{MeI}$ and $\mathrm{K}_{2} \mathrm{CO}_{3}$ to afford $\mathbf{1}$. The ${ }^{1} \mathrm{H}$ NMR spectrum of synthesized 1 was identical to the literature data for $\mathbf{1},{ }^{9}$ confirming the macaranoyl structure of 27-31.

Diaryl ether $\mathbf{2 7}$ was also isolated as a rotameric mixture (Figure 2). The ${ }^{1} \mathrm{H}$ NMR spectrum of 27 in acetonitrile- $d_{3}$ at $24{ }^{\circ} \mathrm{C}$ contained signal pairs, which appeared broadened in the 3.6-5.3 ppm region. While some of the broad signals became sharp at $0{ }^{\circ} \mathrm{C}$, almost all signals in that range were broadened at $50{ }^{\circ} \mathrm{C}$. Coalescence of a pair of the broad signals was detected at $75^{\circ} \mathrm{C},{ }^{21}$ indicating that the rotation barrier of 27 was lower than that of 26. This difference was attributed a decrease in steric hindrance resulting from the transformation of the ketal moiety of $\mathbf{2 6}$ to the benzyloxy moiety of $\mathbf{2 7}$. Although tri- or tetra$o$-substituted diaryl ethers can exhibit atropisomerism, ${ }^{22}$ this feature was not observed in previously synthesized diaryl ether compounds. ${ }^{8}$ Rotamers of $\mathbf{2 8}$ were also detected in the ${ }^{1} \mathrm{H} /{ }^{13} \mathrm{C}$ NMR spectra at $22{ }^{\circ} \mathrm{C}$, indicating that the presence of rotamers is specific to the macaranoyl structure.

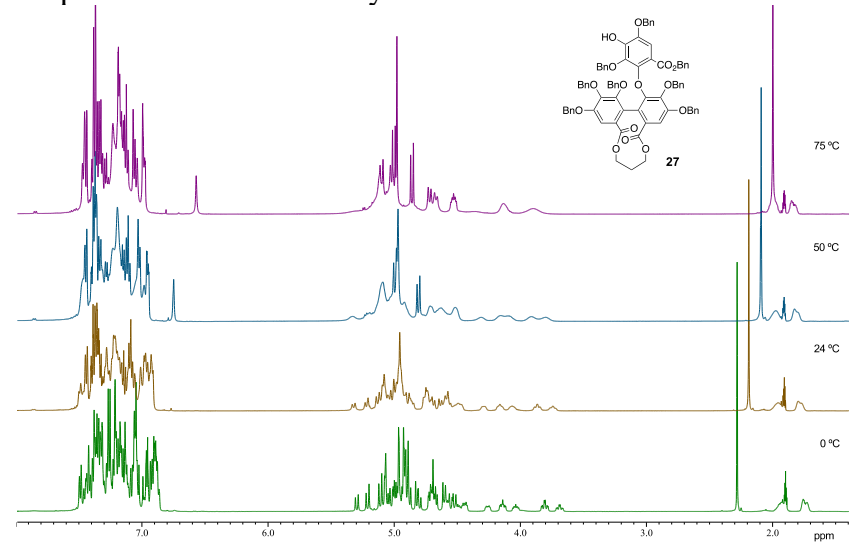

Figure 2. ${ }^{1} \mathrm{H}$ NMR spectra of 27 in acetonitrile- $d_{3}(500 \mathrm{MHz})$ at various temperatures.

In summary, we succeeded in a practical synthesis of the macaranoyl group by expanding our established synthetic procedures for the $\mathrm{C}-\mathrm{O}$ digallate structure. The oxa-Michael addition/elimination reaction using phenol $\mathbf{2 0}$ and $o-\mathrm{Qk} \mathbf{2 1}$ gave a satisfactory yield of $\mathbf{2 6}$ upon addition of 18-crown-6, which enhanced the reactivity of $\mathbf{2 0}$, and by performing the reaction in the dark, the self-aromatization of $\mathbf{2 1}$ was suppressed. $\mathrm{NaBH}_{4}$ mediated reductive aromatization of $\mathbf{2 6}$ provided diaryl ether $\mathbf{2 7}$, which was readily transformed to $\mathbf{2 9}$. We additionally discovered that $\mathbf{2 6}$ and $\mathbf{2 7}$ existed as rotational mixtures owing to the presence of the $\mathrm{C}-\mathrm{O}$ chiral axis. This observation demonstrates the robustness of our method and suggests the possibility of its application to the synthesis of other $\mathrm{C}-\mathrm{O}$ digallate structures. We intend to report the synthesis of ellagitannins with a macaranoyl group in the near future.

\section{ASSOCIATED CONTENT}

\section{Supporting Information}

The Supporting Information is available free of charge on the ACS Publications website.

Experimental procedures, analytical data, and copies of the ${ }^{1} \mathrm{H}$ and ${ }^{13} \mathrm{C}$ NMR spectra for all new products (PDF).

\section{AUTHOR INFORMATION}

\section{Corresponding Author}

*ikeuchi@sci.hokudai.ac.jp

\section{Present Addresses}

$\S$ Faculty of Pharmaceutical Sciences, Tokushima Bunri University, 180 Nishihama-Boji, Yamashiro-cho, Tokushima 770-8514 Japan

\section{Author Contributions}

The manuscript was written through contributions of all authors. All authors have given approval to the final version of the manuscript.

\section{ACKNOWLEDGMENT}

We are very grateful to Prof. Hidetoshi Yamada, who passed away on November 23, 2019, for his dedication to us. We thank Prof. Takashi Tanaka at Nagasaki University for providing ${ }^{1} \mathrm{H}$ NMR spectrum data of $\mathbf{1}$. We also thank Osaka Synthetic Chemical Laboratories, Inc. for their provision of EDCI·HCl. We also acknowledge support from the MEXT-supported the program for the Strategic Research Foundation at Private Universities (S1311046), and JSPS KAKENHI (Grant Number JP16H01163 in Middle Molecular Strategy, and JP16KT0061).

\section{REFERENCES}

(1) (a) Quideau, S.; Feldman, K. S. Chem. Rev. 1996, 96, 475-503. (b) Quideau, S. Chemistry and Biology of Ellagitannins-An Underestimated Class of Bioactive Plant Polyphenols; World Scientific: Singapore, 2009. (c) Quideau, S.; Deffieux, D.; Douat-Casassus, C.; Pouységu, L. Angew. Chem. Int. Ed. 2011, 50, 586-621.

(2) (a) Schmidt, O. T.; Mayer, W. Angew. Chem. 1956, 68, 103-115. (b) Haslam, E. Gallic Acid and Its Metabolites. In Plant Polyphenols, Hemingway, R. W., Laks, P. E., Eds.; Springer: Boston, MA, 1992; Vol. 59, pp 169-194. (c) Haslam, E. Che Farò Senza Polifenoli? In Plant Polyphenols 2, Gross, G. G.; Hemingway, R. W., Yoshida, T., Branham, S. J., Eds.; Springer: Boston, MA, 1999; Vol. 66, pp 15-40. (3) Okuda, T.; Yoshida, T.; Hatano, T., Phytochemistry 1993, 32, 507-521.

(4) Pouységu, L.; Deffieux, D.; Malik, G.; Natangelo, A.; Quideau, S. Nat. Prod. Rep. 2011, 28, 853-874.

(5) (a) Feldman, K. S.; Quideau, S.; Appel, H. M. J. Org. Chem. 1996, 61, 6656-6665. (b) Feldman, K. S.; Lawlor, M. D. J. Am. Chem. Soc. 2000, 122, 7396-7397.

(6) (a) Shioe, K.; Ishikura, S.; Horino, Y.; Abe, H. Chem. Pharm. Bull. 2013, 61, 1308-1314. (b) Abe, H.; Kato, Y.; Imai, H.; Horino, Y. Heterocycles 2018, 97, 1237-1247.

(7) (a) Abe, H.; Sahara, Y.; Matsuzaki, Y.; Takeuchi, Y.; Harayama, T. Tetrahedron Lett. 2008, 49, 605-609. (b) Abe, H.; Ishikura, S; Horino, Y. Synthesis 2016, 27, 859-863.

(8) (a) Hirokane, T.; Hirata, Y.; Ishimoto, T.; Nishii, K.; Yamada, H. Nat. Commun. 2014, 5: 3478. (b) Konishi, H.; Hirokane, T.; Hashimoto, H.; Ikeuchi, K.; Matsumoto, S.; Wakamori, S.; Yamada, H. Chem. Commun. 2020, 56, 3991-3994.

(9) Lin, J.-H.; Ishimatsu, M.; Tanaka, T.; Nonaka, G.; Nishioka, I. Chem. Pharm. Bull. 1990, 38, 1844-1851.

(10) Please see SI-S1 for the preparation method of phenols 11, 12, and 20.

(11) (a) Quideau, S.; Looney, M. A.; Pouységu, L.; Ham, S.; Birney, D. M. Tetrahedron Lett. 1999, 40, 615-618. (b) Gu, Z.; Zakarian, A. Org. Lett. 2011, 13, 1080-1082.

(12) Luche J.-L. J. Am. Chem. Soc. 1978, 100, 2226-2227.

(13) We also attempted oxa-Michael addition/elimination reactions using $\mathbf{4}$ and 11, but the desired products were not obtained.

(14) Paquette, L. A. Potassium Carbonate-18-Crown-6. In Encyclopedia of Reagents for Organic Synthesis, 2nd ed.; Paquette, L. A., Crich, 
D., Fuchs, P. L., Molander, G. A., Eds.; Wiley: New York, 2009; Vol. 10, pp 8142-8144.

(15) We always use the Bn group for the phenol protections in the ellagitannin synthesis. See: (a) Yamada, H.; Nagao, K.; Dokei, K.; Kasai, Y.; Michihata, N. J. Am. Chem. Soc. 2008, 130, 7566-7567. (b) Yamaguchi, S.; Ashikaga, Y.; Nishii, K.; Yamada, H. Org. Lett. 2012, 14, 5928-5931. (c) Kasai, Y.; Michihata, N.; Nishimura, H.; Hirokane, T.; Yamada, H. Angew. Chem. Int. Ed. 2012, 51, 8026-8029. (d) Yamaguchi, S.; Hirokane, T.; Yoshida, T.; Tanaka, T.; Hatano, T.; Ito, H.; Nonaka, G.-I.; Yamada, H. J. Org. Chem. 2013, 78, 5410-5417. (e) Michihata, N.; Kaneko, Y.; Kasai, Y.; Tanigawa, K.; Hirokane, T.; Higasa, S.; Yamada, H. J. Org. Chem. 2013, 78, 4319-4328. (f) Yamada, H.; Ohara, K. Ogura, T. Eur. J. Org. Chem. 2013, 7872-7875. (g) Hirokane, T.; Ikeuchi, K.; Yamada, H. Eur. J. Org. Chem. 2015, 33, 7352-7359. (h) Kaneko, Y.; Wakamori, S.; Ikeuchi, K.; Ohara, K.; Tanaka, T.; Yamada, H. Synthesis 2017, 49, 5003-5006. (i) Ikeuchi, K.; Ueji, T.; Matsumoto, S.; Wakamori, S.; Yamada, H. Eur. J. Org. Chem. 2020, 2077-2085. (j) Wakamori, S.; Matsumoto, S.; Kusuki, R.; Ikeuchi, K.; Yamada, H. Org. Lett. 2020, 22, 3392-3396. (k) Matsumoto, S.; Wakamori, S.; Nishii, K.; Tanaka, T.; Yamada, H. Synlett 2020, DOI: 10.1055/s-0040-1707812.

(16) (a) Amakura, Y.; Yoshida, T. Chem. Pharm. Bull. 1996, 44, 1293-1297. (b) Amakura, Y.; Kawada, K.; Hatano, T.; Agata, I.; Sugaya, T.; Nishibe, S.; Okuda, T.; Yoshida, T. Can. J. Chem. 1997, 75, 727-733.
(17) (a) Zhao, M.; Li, J.; Mano, E.; Song, Z.; Tschaen, D. M.; Grabowski, E. J. J.; Reider, P. J. J. Org. Chem. 1999, 64, 25642566. (b) Wakimoto, T.; Asakawa, T.; Akahoshi, S.; Suzuki, T.; Nagai, K.; Kawagishi, H.; Kan, T. Angew. Chem. Int. Ed. 2011, 50, 1168-1170. (18) Kumarasamy, E.; Raghunathan, R.; Sibi, M. P.; Sivaguru, J. Chem. Rev. 2015, 115, 11239-11300.

(19) Although 16 also appeared to be a rotameric mixture at $24^{\circ} \mathrm{C}, \mathbf{1 4}$ was not, suggesting that the ester moieties on the $o$-Qk ring of $\mathbf{1 6}$ and $\mathbf{2 6}$ are required to establish the $\mathrm{C}-\mathrm{O}$ chiral axis. Dicarboxylic acid $\mathbf{2 9}$ was also isolated as a rotameric mixtures, indicating that the propane tether of $\mathbf{2 6}$ was not involved in the generation of the rotamers.

(20) TMS diazomethane was used for the methylation to eliminate the risk of isomerization of the macaranoyl skeleton of $\mathbf{3 0}$ into the tergalloyl and valoneoyl skeletons via Smiles rearrangement. See Ref. 16a for details.

(21) The ${ }^{13} \mathrm{C}$ NMR spectrum of 27 also showed a pair of signals corresponding to 27 at $\leq 24^{\circ} \mathrm{C}$. These paired signals coalesced at $50-70^{\circ} \mathrm{C}$. See SI-S7 for details.

(22) (a) Betson, M. S.; Clayden, J.; Worrall, C. P.; Peace, S. Angew. Chem. Int. Ed. 2006, 45, 5803-5807. (b) Clayden, J.; Worrall, C. P.; Moran, W. J.; Helliwell, M. Angew. Chem. Int. Ed. 2008, 47, 32343237. (c) Dinh, A. N.; Noorbehesht, R. R.; Toenjes, S. T.; Jackson, A. C.; Saputra, M. A.; Maddox, S. M.; Gustafson, J. L. Synlett 2018, 29, 2155-2160. 